\title{
POST-TEXTUAL SHAKESPEARE
}

\author{
DOUGLAS M. LANIER
}

No tongue, all eyes! Be silent.

(The Tempest, 4.I.59)

In 2007, a curious billboard appeared in London advertising the move from Waterloo to St Pancras stations for the London hub of the Eurorail train to Paris. Above the logo 'London is changing' was featured the image of a skeleton kneeling on a stage, holding in his bony hand the fully fleshed head of a man who looked back at the skeleton's skull with astonishment. In 2004 and 2005 , a poster campaign in Swiss cities advertised the Espace 2 channel of Radio Suisse Romande with the image of two teens kissing in a subway train filled with inattentive passengers, accompanied by the simple, one-word caption, 'Shakespeare.' These advertisements provoke a deceptively simple question: is this Shakespeare? In what sense Shakespeare? To ask the question 'is this Shakespeare?' is to ponder the nature of the boundaries that extend around the designation 'Shakespearian', laden though that designation is with cultural power and value. Like lines on a map, those boundaries may have the illusion of permanence at a given moment, but in reality they are always in flux, constantly being renegotiated in response to a variety of cultural forces. Here I will be discussing a particular kind of limit case that poses a challenge to one of the founding principles of Shakespeare studies. My claim, in a nutshell, is that both popular culture and avantgarde performance have transgressed and redrawn the boundary of what can constitute 'Shakespeare' with ever-greater insistence in the last twenty years, and that they have done so in response to a newly powerful cultural dominant in the late twentieth and early twenty-first century. Though I will eventually turn to two noteworthy recent performances of Shakespeare, I begin with examples from advertising because advertising stands at the intersection of popular culture and avant-garde aesthetics, amplifying (and thus making visible) ideological and representational strategies it borrows from elsewhere. Though the aims of the ads and the performances are quite different, what they reveal are the traces of processes at work in popular and performance culture more generally. I hope to suggest how, under the pressure of mass mediatization, contemporary Shakespeare may be undergoing something of a paradigm shift that raises foundational questions about how we, as Shakespearian professionals, conceptualize the 'essential' or 'authentic' Shakespeare and situate his cultural value.

The challenge posed by these ads is that there is not a single word from Shakespeare's text in either example, despite the fact that they depend for their effect on being identified as 'Shakespearian'. Like so much of contemporary advertising, these examples are driven almost entirely by arresting images. What text there is has been pared to the absolute minimum and the sales information has been squeezed to the edges of the frame. If we compare these ads to Shakespeare-themed ads from earlier periods, we immediately recognize a very different ratio of visual image to word. An ad for Ridge's Baby Food from I885, for example, also uses Shakespeare to reinforce its message, but Shakespearian authority is vested in its three 


\section{DOUGLAS M. LANIER}

textual citations - 'What say these young ones' (King John, 2.I.522), 'It be wholesome food' (The Taming of the Shrew, 4.3.I6), and 'The food that to him ... is . . luscious' (Othello, I.3.347) - rather than the image of mother and nurse feeding a happy child. ${ }^{\mathrm{I}}$ This ad would not be recognized as Shakespearian at all were it not for for quotations from Shakespeare's text. A remarkable ad for Olin Industries from 1945 features an image of post-war ruins, amidst which we see a fallen bust of Shakespeare and a thriving flower; the prominently featured citation, 'out of this nettle, danger, we pluck this flower, safety' (I Henry IV, 2.4.9), summarizes the ad's message - post-war Europe provides Olin with lucrative manufacturing opportunities - as a Shakespearian aphorism. ${ }^{2}$ In the earlier examples, invoking Shakespeare in service of sales seems to require the presence of Shakespeare's text. But in the contemporary examples with which I began this article, insofar as we are willing to grant that they are Shakespearian, the Shakespearian meaning and authority they invoke is decidedly post-textual, independent of Shakespeare's words.

That is not to say that the contemporary ads are post-textual in the same way. In the case of the Eurostar ad, ${ }^{3}$ our identification of it as Shakespearian turns on a visual commonplace, Hamlet holding Yorick's skull, one of a small set of iconic images that signal 'Shakespeare' to the viewer Romeo at Juliet's balcony, Julius Caesar in a toga, the Droeshout engraving in the First Folio, to name a few. However, this image is not merely of Hamlet, but of an outdated mode of performing Hamlet - behind the skeleton are painted flats in Romantic style; there is a hint of proscenium staging; the skeleton's gesture is formal and declamatory; the human head in the skeleton's grasp has the windswept look and passionate expression of a Romantic portrait. These visual articulations of the Hamlet commonplace make 'Shakespeare' into an icon of old-fashionedness against which the Eurostar can define itself as contemporary, cosmopolitan, cool. For those viewers who might remember the passage from which this is taken 'where be your gibes now?' - Hamlet's meditation on the irony of Yorick's now faded triumph is turned into modernity's meditation on Shakespeare's once glorious cultural position, his having now wasted away to a skeleton chatting to a disembodied, no doubt overly intellectual head. But, and this is the crucial point, the ad doesn't assume we remember this passage. Its horizon of recognition is visual, not textual. Simple though it may be, the image depends upon our picking up visual subtleties to understand it - it is simple, but not simplistic. The ad for Espace 2 is more elliptical, by design. ${ }^{4}$ In fact, the connection to Shakespeare is prompted only by the caption. Is the association with Shakespeare as poet of eternal love? Is the ethnic difference between the MiddleEastern man and white European woman evocative of the kind of cultural divide that separates Romeo and Juliet? Are we meant to link the particular shade of blue that dominates the ad with the shade of blue that suffuses the pool scene in Baz Luhrmann's Romeo + Juliet where the lovers share their first kiss? Is the fluorescent lighting meant to be reminiscent of the fluorescent-light crosses

I The Illustrated Sporting and Dramatic News, I 2 December I 885 , p. 323. It is noteworthy that the ad explicitly identifies each textual citation by source play, act and scene.

${ }^{2}$ Life Magazine, Io September 1945, p. I I5. This ad identifies the textual citation only by source play (listed just as Henry IV), and it adds the name 'Shakespeare', as if in recognition of the target reader's potential doubt about its author.

3 This ad was part of a campaign in late 2007 designed by LEG SA, based in Paris. Each ad in the campaign took a traditional image of British culture and gave it a visual twist from contemporary British culture: replacing a grenadier guard outside St James's Palace, for example, was the character Po from the children's show Teletubbies (produced in the UK); on the front of a 2,55 note is the grinning face of $\mathrm{Mr}$ Bean, Rowan Atkinson's screwball character from the popular television show Mr Bean.

4 This ad is part of a campaign designed by the Swiss firm Rive Gauche Communications for Espace 2, dating from 2004. Other ads in the campaign followed the pattern of a single 'cultural' name accompanied by an initially cryptic image that depended on the viewer's parsing the allusion. A picture of hazelnuts, nutcracker and a glass of wine, for example, bore the label 'Tchaikovsky'; a shot of a digital clock reading '23.59' was labelled 'Monk' (an allusion to Theolonious Monk's song 'Round Midnight'); and a closeup of a worker wiping his grimy hands with a rag had the caption 'Sartre' (an allusion to his play Dirty Hands). 


\section{POST-TEXTUAL SHAKESPEARE}

in the final scene of Luhrmann's film? The cryptic caption 'Shakespeare' prompts us to analyse the image for cues and rifle through our archive of Shakespearian visual references to make sense of it. That process requires little substantial recourse to the Shakespeare text. And once we've parsed the image, the ad's message comes into view: it demonstrates the contemporaneity and universality of high culture, what Espace 2 calls 'la vie côté culture', in particular its relevance to a hip youth market. Our very ability to make sense of the cryptic connection between Shakespeare and this image of lovers identifies our appropriateness as Espace 2 listeners, or so the ad seems to say: we have sufficient high cultural literacy to recognize the general resonances of 'Shakespeare' but also sufficient pop cultural literacy to recall specific images from Luhrmann's Romeo + Juliet. And since we, not the ad, make the connection explicit, we are flattered by our own capacity to read the allusive link - and, by implication, this is the kind of savvy listener who is 'cultural' and tunes into Espace 2. Both ads trade on Shakespeare's cultural capital, but that cultural capital is located primarily in our ability to recognize Shakespeare as image, not Shakespeare as text; the primary frame of reference is visual, not literary, culture. This is post-textual Shakespeare.

In one sense, post-textual Shakespeare is nothing new. The dumb show and theatrical dance were features of the early modern stage, manifest in Shakespeare's work in the dumb shows in Hamlet's Mousetrap, Macbeth and Pericles, and the dance sequences in A Midsummer Night's Dream and The Tempest. The Boydell Shakespeare Gallery at the end of the eighteenth century capitalized upon the nascent trend of Shakespeare painting, shifting the focus from capturing actors performing Shakespeare to converting Shakespearian characters and narratives themselves into visual images. The nineteenth century, besides being the heyday of the Shakespeare illustration, saw other attempts to convert Shakespeare to non-textual form dance in the form of Shakespeare ballet, ${ }^{5}$ and music in the form of symphonic programme music. ${ }^{6}$ And the first two and a half decades of the twentieth century generated a robust tradition of silent
Shakespeare on film. ${ }^{7}$ What distinguishes these wordless Shakespeares from contemporary posttextual Shakespeare are several factors. First, these earlier examples are not so closely linked with the prevailing media for Shakespeare in their day. That is, earlier non-textual Shakespeares tended to be alternatives to print and stage Shakespeares, not substitutes for them. By contrast, contemporary post-textual Shakespeare is intimately linked with the unprecedented dominance of mass media and the ways in which those media have shifted the dominant modalities of communication away from text. There is also an historical dimension of cultural politics at work here. In the nineteenth century the Shakespearian text was elevated to the status of secular scripture; late in the century there emerged a class of hermeneutic professionals devoted to methodical study of an 'authentic' Shakespearian text they sought to establish, professionals who displaced the heretofore amateur and journalistic critical tradition which had focused primarily on biographical criticism and

5 Examples include Antony and Cleopatra (as Antoine et Cléopâtre, first adapted I76I); The Tempest (first adapted I774); Macbeth (first adapted I785); Hamlet (first adapted I788); Othello (first adapted I818); and A Midsummer Night's Dream (first adapted I 855). Romeo and Juliet is, by far, the Shakespeare play most often adapted to ballet form; it was first adapted in I 8 I I. Adaptation of Shakespeare to ballet form has remained popular throughout the twentieth century, particularly when accompanied by orchestral suites written on Shakespearian themes.

6 Examples include Beethoven's Coriolan (I 80I); Mendelssohn's A Midsummer Night's Dream Overture (1826, revised I842); Berlioz's Ouverture de la Tempête (I830, later incorporated into Lélio ou Le Retour à la vie), Roméo et Juliette (I839), and Marche funèbre pour la dernière scène d'Hamlet (I 844); Liszt's Hamlet (I 858), Tchaikovsky's Romeo and Juliet Fantasy Overture (I 869), The Tempest (I 873) and Hamlet (I 888); Richard Strauss's Macbeth (I 888); and Elgar's Falstaff (I9I3). This genre retained its popularity in the twentieth century.

7 I have excluded one seemingly obvious item on this list, sign-language Shakespeare, because sign-language is indeed a language, though in performance signing shares qualities with physical theatre. For a cogent discussion of sign-language Shakespeare and its relationship to some of the issues raised in this article, see Peter Novak, "Where Lies Your Text?': Twelfth Night in American Sign Language Translation', Shakespeare Survey 61 (Cambridge, 2008), 74-90. 


\section{DOUGLAS M. LANIER}

debates about Shakespearian performances. By situating themselves as keepers of the historical text, these Shakespearian professionals, who would soon become central to the establishment of English as an academic discipline, drove a wedge between popular culture and textual Shakespeare. Though Shakespeare's value as a cultural icon continued to be recognized across the cultural divide of highbrow and lowbrow, his language was to become a sticking point, too tied to academic professionals and too archaic and intellectualized to be easily assimilable to pop culture, except as the object of parody. Indeed, for much of the twentieth century Shakespeare's text served primarily as a foil against which pop culture could define itself as modern, democratic, immediate and fun. And yet, because Shakespeare remained a potent cultural icon, twentieth-century popular culture is also marked by repeated efforts to loosen the ties between Shakespeare and the words he wrote, in an effort to recover Shakespeare's cultural authority for wider popular appropriation.

Two primary cultural drives underlie Shakespeare's contemporary post-textualization. One is what W. J. T. Mitchell has called 'the pictorial turn' in late twentieth-century culture, a decisive shift in the relative ratios of image and word in the dominant media of our day. ${ }^{8}$ Those media - advertising, film, television, the Internet - offer more information visually and with greater visual density; new technologies allow greater control over the content of images than ever before, and we are expected to process images at greater speeds. This visual information we now routinely process from media depends upon, and at the same time escalates, a heightened visual literacy which has become a crucial part of postmodern experience. In the nineties, Shakespeare film sought to develop strategies through which Shakespeare might be recast more definitively in visual terms, the language subordinated if not eliminated entirely. To illustrate, we might compare Olivier's and Branagh's handling of the 'idol ceremony' speech in their films of Henry $V$. Olivier's visuals - the king blank-faced by the campfire as dawn breaks over his shoulderare subordinated to the spoken text, which is delivered in voiceover. Turn off the soundtrack, and one would be hard-pressed to work out what is happening. Branagh's performance is just as lowkey, but as he walks through the camp the images behind him - a cart piled with flags, shields and battle regalia, a humble soldier asleep in another cart - convey the contrast between the empty accoutrements of royalty with the peaceful rest of the commoner and thereby shift the ratio of image and word in the direction of image. The doubled prologue of Baz Luhrmann's Romeo + Juliet explicitly thematizes this change. At first the play's prologue is delivered to us as if on a television newscast in which the announcer's words trump the banal (and initially small) image, but then we are unexpectedly pulled into the film's postmodern mediaverse where the very same prologue is redelivered to us in hypervisual terms. Each phrase of the prologue is converted before our eyes into visuals, the words themselves becoming images which accelerate beyond our ability to read them, the entire sequence acclimatizing the viewer to the accelerated speed and hyperallusive

\footnotetext{
8 See W. J. T. Mitchell, Picture Theory: Essays on Verbal and Visual Representation (Chicago, I995), pp. I-23 (the phrase 'pictorial turn' first appears on page I I). Though Mitchell acknowledges the pictorial turn in modern media, he stresses the continuing interplay between word and image in contemporary culture rather than some final triumph of image over word. In his most recent work, Mitchell has insisted upon the mixed nature of all media: see his 'There are No Visual Media', Journal of Visual Culture, 4 (2005), 257-66. Nevertheless, the rise of 'visual culture' as a discipline within the academy testifies to contemporary culture's emphasis on the image. For an introduction to issues in visual culture, see Nicholas Mirzoeff, The Visual Culture Reader (London, 2002, 2nd edn); Marita Sturken and Lisa Cartwright, Practices of Looking: An Introduction to Visual Culture (Oxford, 2007, 2nd edn); and Stanley Elkins, Visual Studies: A Sceptical Introduction (London, 2003). Jonathan Crary's Techniques of the Observer: On Vision and Modernity in the Nineteenth Century (Cambridge, MA, I992) stresses that contemporary visual culture (and the anxieties which attend it) has its origins in nineteenth-century developments in media and performance technology. Crary's discussion accords in many ways with Richard W. Schoch's overview of nineteenth-century scenography in 'Pictorial Shakespeare', in Stanley Wells and Sarah Stanton, eds., The Cambridge Companion to Shakespeare on Stage (Cambridge, 2002), pp. 58-75.
} 


\section{POST-TEXTUAL SHAKESPEARE}

visual flow of the film that follows. The nineties generated several cinematic strategies - Branagh's illustrational style, Luhrmann's hypervisual style, Julie Taymor's postmodern arthouse style, Hoffman and Radford's heritage film style - but all worked to tilt the sensory balance in the direction of image and away from Shakespeare's language. By the time we get to the end of the decade, Shakespeare on film seemed increasingly able to do without his language entirely, as a number of teen modernizations seemed to illustrate. To put this in business parlance, once rendered in posttextual form, Shakespeare was able to become fully 'cross-platform content'.

The other main impetus behind Shakespeare's recent post-textualization is globalization. As Arjun Appadurai notes, globalization tends to favour free transnational flows of people, money, goods and technologies. ${ }^{9}$ That which impedes those flows risks being eliminated, marginalized or transmuted into more fluid form. So it is with Shakespeare: his work is a valuable resource, but because of its textual form, it has limited cross-cultural fungibility. Though translation is one means for engaging the problem, it ultimately arrives at the very problem it seeks to remedy - linguistic boundaries. Non-textual forms - physical movement, music and especially image - would seem to offer much freer cross-cultural communication. In short, images travel well and, in Shakespeare's case, visual media would seem more commensurate with his putative universality. This point was made long ago by Georges Méliès's 1907 silent film Le Rêve de Shakespeare (aka Shakespeare Writing Julius Caesar). ${ }^{\text {Io }}$ The plot is simple: frustrated by writer's block as he tries to compose a script, Shakespeare settles into a daydream at his desk. Behind him, in one of Méliès's trick optical shots, appears an elaborate version of the assassination of Julius Caesar, clearly the vision Shakespeare sees in his mind's eye. The scene then returns to Shakespeare's study, where Shakespeare dances merrily about and, in imitation of what he has imagined, he stabs a loaf of bread with glee. The film's final image is a cross-fade from the living Shakespeare, with arms confidently folded, to a bust of Shakespeare, surrounded by the flags of many nations. Méliès is claiming that Shakespeare is a film-maker avant la lettre, that is, the source and power of his work springs ultimately from visual images, not words. (It's no accident that Méliès the film-maker himself plays Shakespeare.) It is because Shakespeare's imagination is fundamentally cinematic, grounded in the 'universal' vocabulary of silent images, that, Méliès suggests, his status as a cultural icon can be international. The blockage that the writing Shakespeare suffers at the start of the film is thus as much cultural as it is personal, and shifting from text to image allows Shakespeare to move past it. Shakespeare Writing Julius Caesar touts the power and global reach of its own silent medium, and it maintains that the power of Shakespeare, the 'universal' poet, accords with - or ought to accord with - that medium's non-textual nature. With this film of Shakespeare's daydream, Méliès announces the cultural dream that would be pursued by popular culture and mass media throughout the twentieth century, one that has been crucial to Shakespeare's accelerated globalization in image and film in the past twenty years.

Some caveats here. First and obviously, all nontextual modes of expression include points of reference and expressive elements which situate them locally. The claim that images and movement are legible across all cultures has been a persistent

9 Arjun Appadurai, 'Disjuncture and Difference in the Global Cultural Economy', in Modernity at Large: Cultural Dimensions of Globalization (Minnesota, I996), pp. 27-47.

Io This film is lost, but Robert Hamilton Ball prints the entirety of the scenario (as well as a surviving photo) and briefly discusses it in Shakespeare on Silent Film: A Strange Eventful History (London, I968), pp. 35-6. See also Judith Buchanan, Shakespeare on Silent Film: An Excellent Dumb Discourse (Cambridge, 2009), p. I I9. Buchanan stresses that Méliès's vision of an international, 'universal' bard was at odds with the more self-consciously nationalistic and corporate appropriations of Shakespeare by other silent film producers, most notably Vitagraph. Though Buchanan's point is quite correct, it nevertheless seems noteworthy that the competition between Vitagraph and other film producers over appropriation of Shakespeare was energized at least in part by the potential of Shakespeare on silent film to circulate internationally more freely than, say, theatrical performances. 


\section{DOUGLAS M. LANIER}

problem for intercultural performance and has opened it up to charges of exoticism, incoherence or colonial appropriation. ${ }^{\text {II }}$ Nevertheless, in an age of the Internet and digital media the accelerated global circulation of what were once local visual cultures has demonstrably lessened the gap between local knowledge and cross-cultural consumption in a way not matched by textual culture. One might think, for example, of how the visual vocabularies of Japanese manga or Bollywood cinema have become a familiar part of a globalized image culture in the past twenty years. A second related issue involves the problem of mistaking the cultural dominance of certain visual vocabularies the styles and reference points of Western mass media, for example - as evidence of their 'universality' rather than their dominance being a function of power relations between competing media at the present moment. A third caveat returns us once again to advertising and the relationship of posttextual Shakespeare to circulations and transformations of global capital, both economic and symbolic. So long as Shakespeare's cultural authority is located in his language, capacity for cross-cultural appropriation of that authority, I have been arguing, has been seen as fraught with limitations. But if Shakespeare can be refigured as post-textual, a matter of images not words, the considerable cultural capital he represents can become more freely fungible, capable of much wider use in the marketplace. Shakespeare's cultural capital, in short, follows the logic of global capital in an age of mass media. This helps us to understand the symbiotic relationship between the cinematizing of Shakespeare in the nineties and the concomitant accelerated circulation of Shakespeare in global culture at century's end (though, of course, the latter is multiply determined). If the project of resituating Shakespeare on film involved making Shakespeare predominantly visual and loosening his long-standing relationship to text, that process also contributed to the general sense that Shakespeare, recast in this way, might circulate freely - or at least more freely - across cultural borders.

I've been suggesting that post-textual Shakespeare has been the province of mass media and popular culture, but two recent theatrical productions suggest that it is also becoming a stage phenomenon. I want briefly to examine the work of two companies that have staged performances of Shakespeare without words, the Synetic Theater, based in Washington DC, and Punchdrunk, based in London, in particular Synetic Theater's 20 Io production of Othello, and Punchdrunk's Sleep No More, its production of Macbeth, first staged in 2003 and revived in 2009. These provocative productions seek to align Shakespeare with what has come to be called 'physical theatre', a mode of performance that has come to prominence in the last two decades. Physical theatre is a hybrid of many different performance practices - mime, clowning, dance, gymnastics, street performance, site-specific theatre and performance art. ${ }^{\mathrm{I} 2}$ At the heart of its many forms, however, are two concerns, bodily performance and the highlighting of physical presence. As the term 'physical theatre' implies, emphasis falls strongly, often exclusively, on bodily movement and visuals rather than on words to convey content. The key touchstone here is of course Antonin Artaud, with his call for a primordial, pre-verbal theatre that affects spectators viscerally. ${ }^{\mathrm{I}}$

I A cogent overview of these issues can be found in W. B. Worthen, 'Shakespearean Geographies', in Shakespeare and the Force of Modern Performance (Cambridge, 2003), pp. I I768, esp. pp. I23-34. See also Patrice Pavis, 'Introduction: Toward a Theory of Interculturalism in Theatre?', in The Intercultural Performance Reader, ed. Patrice Pavis (London, I996), pp. I-2I.

I2 For introductions to this highly varied mode of performance, see Simon Murray and John Keefe, Physical Theatres: A Critical Introduction (London, 2007), and Josephine Machon, (Syn)aesthetics: Redefining Visceral Performance (Basingstoke, 2009). According to Murray and Keefe, the term 'physical theatre' was first applied to the work of the company DV8 in 1986. Examples of DV8's productions can be found on two DVDs, DV8: The Cost of Living (Digital Classics, 2006) and DV8: Physical Theatre (Arthaus, 2007).

I3 See The Theatre and Its Double, trans. Mary Caroline Richards (New York, I994), which contains the essay 'No More Masterpieces'. Artaud's first manifesto for a theatre of cruelty succinctly lays out its aims: 'instead of continuing to rely upon texts considered definitive and sacred, it is essential to put an end to the subjugation of the theater to the text, and to recover the notion of a kind of unique 


\section{POST-TEXTUAL SHAKESPEARE}

Physical theatre both rejects the primacy of language and self-consciously foregrounds the power of its physical presence. Conjoining Shakespeare and physical theatre is by no means obvious or inevitable, particularly if we recall Artaud's battle cry, 'no more masterpieces'. To make that link is fundamentally to recast Shakespeare's relationship to stage performance and text and thus to recast what constitutes the 'essence' of the Shakespearian. In the Shakespeare productions of Punchdrunk and the Synetic Theater, there is a productive tension between mass-mediated popular culture and Artaudian physical theatre that surfaces at several levels - in the productions' performance techniques, in the sorts of cultural references they put into play, in the particular quality of experience they seek to give their audiences. Though it is clearly not these companies' intent, their emphasis on the bodily and the visual brings their approach to Shakespeare into affiliation with popular posttextualization of Shakespeare. This conjunction of cultural contexts is, it seems to me, crucial for understanding how these companies reconceptualize Shakespeare and why these performances have been popular with audiences.

\section{SYNETIC THEATER'S OTHELLO}

Synetic Theater ${ }^{\mathrm{I} 4}$ has been producing wordless Shakespeare performances since 2002, when it premièred Hamlet . . the rest is silence. Since then, it has produced adaptations of Macbeth, Romeo and Juliet, A Midsummer Night's Dream, Antony and Cleopatra and Othello, with a King Lear its most recent Shakespeare production, as well as other 'classic' tales with wide cultural currency. The company is the brainchild of director Paata Tsikurishvili and his wife and choreographer Irina, both of whom trained in Soviet Georgia with Amiran Shalikashvili, director of the Georgian State Pantomime Theatre. ${ }^{\mathrm{IS}}$ The influence of their background in avant-garde theatre, film and ballet is readily apparent in Synetic's productions. Also noteworthy is the Tsikurishvilis' status as Georgian emigrés in Germany and then the United States. In interview ${ }^{16}$ Paata Tsikurishvili has remarked that having first come to know Shakespeare through translations into his native tongue, he regarded Shakespeare as a Georgian author, but he and his wife's immigration to the West necessitated their cultivating a performance style for Shakespeare legible across cultural and linguistic borders. Paata Tsikurishvili locates Shakespeare's essence in narrative and the emotional states of his characters, elements he regards as transcultural, and so Synetic productions tend to have a strong, linear storyline somewhat unusual for physical theatre. This also explains why the company has preferred Shakespearian tragedy, for Shakespeare's worddriven comedy, observes Paata, is so culturally specific that it is difficult to physicalize. Non-balletic dance and mime are the central components of Synetic's stage vocabulary, combined with original, through-composed music, and often stylized set design and costuming. Abstraction in the production design helps assure that most characters read as types rather than individuals, though in the case of Othello by using different degrees of stylization and naturalism for various characters, the company helps manage the audience's empathy with the tale's protagonists. Many Synetic productions of Shakespeare share a narrative arc, opening with some form of trauma associated with escape, exile and dislocation. We first see Romeo and Juliet trapped in a prisonhouse of gears from which they try unsuccessfully to break free; Midsummer opens with

\footnotetext{
language half-way between gesture and thought' (89). Though it has been highly influential on contemporary theatrical practice, Artaud's stress upon bodily presence and its relationship to primal or direct, unrepresented experience has come in for criticism. See, for example, Jacques Derrida, 'The Theatre of Cruelty and the Closure of Representation', in Writing and Difference, trans. Alan Bass (Chicago, 1978), pp. 232-50, and Philip Auslander, Liveness: Performance in a Mediatized Culture (London, I999).

I4 The term 'synetic', the company's own creation, combines 'kinetic' and 'synthetic', stressing both the basis of the company's productions in bodily movement and its desire to bring together a variety of performance arts into a single, distinctive, synaesthetic whole.

Is Additional biographical information is available at www. synetictheater.org/aboutus/mission/html.

i6 Conducted by phone, 30 July 20 Iо.
} 


\section{DOUGLAS M. LANIER}

the birth of the Indian boy and death of his mother; the initial image of Antony and Cleopatra is of the struggle for power between Cleopatra and Ptolemy, presented as a literal scramble up the staircase of an Egyptian temple where there awaits a writhing snake-like dancer, symbol of Egypt's seductive power. Othello opens with a double trauma, reflecting the sense that the play has double protagonists. The production begins with Iago centre-stage in dappled light resembling a net, vacillating between laughter and regret; this image is also the play's final tableau. Othello first appears as one of a group of slaves tormented by Turkish captors. As one of the slaves, a black woman, dies from being beaten, she gives Othello the handkerchief he will eventually give to Desdemona, prompting Othello to lead a rebellion and ally himself with the Venetians. The final moments of Synetic productions often recall the opening traumas; there the protagonist comes tragically to recognize how fully that moment has shaped his or her psychology or the events of the narrative. Antony and Cleopatra, for example, ends where it began, on the stairs of the Egyptian temple, and Othello too has a circular structure. Haunting many of Synetic's Shakespeare productions, and particularly its Othello, are issues of exile and cultural dislocation, notable themes given the transcultural ambitions of the performance style.

Synetic's Othello is exemplary of the company's approach to Shakespeare. The set is composed of triangles, appropriately enough, which evoke shards of broken glass. The score by Konstantine Lortkipanidze, composer for many of the company's productions, underscores and intensifies the emotional tenor of the scenes, serving as a kind of continuous soundtrack for the action. Colourcoding helps those unfamiliar with the narrative to keep the characters straight, but it also works to type the characters: the Turks are in brightly coloured flowing robes with masked faces, the Venetians in black and white stylized Renaissance costumes, Roderigo distinguished from the others by his sickly yellow hat and gloves and flower. More individualized are Othello and Desdemona Desdemona appears all in white and Othello, once he joins the Venetians, is all in black. Othello and
Desdemona are also set apart in their bodily style. The Venetian court often functions as a single synchronized ensemble, whereas Othello and Desdemona move more independently and naturalistically. Although Othello's revolt from slavery would seem to announce race as a central concern, in fact the black and white costuming of Othello and Desdemona rarely reads in terms of racial difference, at least until the final scenes. It's remarkable that race figures so little in Othello's relationship to Venice. When Iago mimes telling Brabanzio that 'an old black ram is tupping your white ewe', the image is presented to us as pantomime comedy, not to be taken seriously; both ram and ewe are played by white actors. Brabanzio's confrontation with Othello early on is the one, very brief instance where Othello's moorishness is at issue. Otherwise, the production focuses far more on sexuality and gender, particularly so in the production's approach to Iago. Like the other Venetians, he is dressed in black and white, but his face is ghoulishly whitedup and his hair punkishly spiked, as if he were both clown and demon. Red accents in his hair and costume indicate buried sexual passion, a point made considerably clearer by the fact that Emilia and Bianca, both openly erotic in this production, are also in red. When Othello is welcomed to Venice and chooses Cassio as his companion, Iago lapses into a frenzy, but it is Othello's love for Desdemona that utterly unhinges him and sets his plotting in motion. This Iago is plagued by pornographic visions. Repeatedly he imagines his lusty wife in Othello's embrace, despite the fact that in Iago's and Emilia's erotic pas de deux over Desdemona's lost handkerchief, her sexual attention is directed entirely towards him. For Iago, Desdemona represents both an ideal of erotic purity Othello has stolen from him and a perverse object of lust he seeks to defile. This becomes amply clear when Iago comforts Desdemona after Othello has publicly humiliated her and then grotesquely tries to steal a kiss. With his plotting Iago seeks to project his own contradictory erotic fantasies and jealousy onto Othello.

A key challenge for physical storytelling is how to reveal the interiority of character, particularly 


\section{POST-TEXTUAL SHAKESPEARE}

when that interiority is at odds with outward appearances, and it is here that Synetic's Othello focuses much of its attention and marks an advance over its previous Shakespeare productions. After Othello makes his first romantic connection with Desdemona, Iago is given a solo scene before a mirror - what amounts to a physical soliloquy. Overcome with rage and grief, he smashes through the mirror and becomes three different characters (two men, one woman), all marked with Iago's distinctive red accents. Thereafter, the three act as a conspiratorial unit, the original Iago often playing 'honest' Iago while the other two Iagos help with his schemes, offer him encouragement and provide him an onstage audience. This approach gives us a bodily analogue for Iago's self-regarding, fractured ego; the fact that his mirror-self splits into male and female suggests that Iago is unable to navigate a crisis of gendered subjectivity and desire. The oversize triangles which dominate the set design, vaguely reminiscent of shards of glass, remind us constantly of Iago's shattered ego-ideal that dominates every aspect of the narrative. A second mirror-soliloquy later on adds to our understanding of his psyche. After the three Iagos watch Othello and Desdemona consummate their relationship, the trio stands again before the shattered mirror. This time the Iagos pull Othello, then Cassio, through the mirror frame into their world, and they play out their fantasies of revenge and control by manipulating Othello and Cassio's movements, miming pulling strings as if the two were puppets. One might expect the third figure in this sequence to be Desdemona, but who next appears is Emilia, dressed seductively in red and eluding Iago's grasp. She and Othello immediately fall into a passionate dance, while the trio of Iagos mime being trapped behind the mirror, forced to watch Iago's perverse projections until lovelorn Roderigo arrives to break the spell. Fractured by fantasies of his own male grandeur and fears of women's erotic independence, Iago undertakes to project his own psychological crisis onto Othello.

That projection becomes quite literal, for a second innovation in this production is its use of minicamera/projectors, the Iagos' weapon of choice.
The Iagos record Cassio's encounters with Desdemona and Bianca, then project fragmented closeups of them onto the set for Othello to see. ${ }^{17}$ This technique of showing the spectator the pornographic couplings Othello imagines has become de rigueur in Othello films of the nineties, of course, but on the stage those projections function rather differently. Though Iago's links to the mirror and the screen suggest a Lacanian scenario, perhaps more interesting here is how film, as technique and as ideological force, is pitted against the world of the stage. Within the fiction, Iago becomes a cinematic adapter, but his films are engines of bodily fragmentation and fetishization, qualities which violate the sort of physical presence and integrity that stage performance affords. Increasingly, the images Iago projects are close-ups of body parts, distorted, magnified, perversely edited. What is more, the Iagos project those images around the stage, so that the images become quite literally the environment, physical and psychological, within which Othello must move. The invasion of projected image into performance space is exploited with great ingenuity. At one point, Othello finds himself pressed between triangles on which are projected Desdemona and Cassio, which he fights to keep apart while preventing himself from being crushed. At another point, Iago holds up a giant version of Desdemona's handkerchief which becomes a screen on which he projects images, while Othello, writhing in anguish, appears as a shadow behind. These projections enervate Othello. Once he enters Iago's world of the shattered yet wrap-around mirror/screen, he becomes trapped in an environment of denarrativized images which feed his fears and fantasies. Iago's moment of triumph comes when Othello picks up the handkerchief that Cassio leaves behind. Pressing it to his face, Othello then places it over his head. This gesture foreshadows his

17 Iago's deployment of modern recording technology in his deception of Othello is not new. In the film adaptation All Night Long (1962, dir. Basil Dearden), the Iago figure Johnny Cousin uses a tape recorder, a hidden microphone and some clever editing to awaken the jealousy of Aurelius Rex, the Othello figure. 


\section{DOUGLAS M. LANIER}

death, signifies discomfort with his own blackness, and obliterates his identity with what has become one of Iago's screens. Eventually even Desdemona's own white dress also becomes a screen for projected images, now from Othello's imagination, and she is murdered, becoming a saintly martyr in death, raised on a cross at the back of the stage.

In the play's final scene, Emilia steals Iago's projector and reveals its images to the onstage crowd who have gathered in Othello's chamber. Here Othello finally recognizes the device's power and his deception. The projector then becomes a weapon with which Emilia, Iago and Othello are stabbed, though when Iago first uses the projector to murder Emilia, it is difficult at first for the spectator to work out just what has happened - notably, having functioned cinematically within the production, the projector doesn't move easily back into the realm of stage illusion where it can function metaphorically. In one of the most fascinating and revealing stage images of the production, after wounding Iago and wresting the handkerchief from him, Othello once again places the white handkerchief over his head and then briefly projects images onto it before killing himself with the projector. Here race and erotic projection briefly converge, for Othello comes to recognize how becoming a screen for Iago's fantasies drew him into racial self-hatred. But what actually emerges here most strongly is not the issue of racial identity at all but the psychological power of the cinematic image, its ability to fragment or dwarf otherwise integral bodies and grotesquely distort or magnify desire, its capacity to overwhelm and invade the psyches of spectators. What emerges, in short, is an allegory of the tension between physical theatre and mediatized culture, a tension which the production, with its combination of live action and state-ofthe-art video technology, participates in as much as it comments upon. If Shakespeare's Othello is a play about the power of storytelling, Synetic's production of Othello addresses competing modalities of non-verbal storytelling in a contemporary context, pitting the physical body and the theatrical against screen images and the videographic. And the final fates of Othello and Iago offer rather different, though in the last analysis both tragic, assessments of the effects of mediatization. In Othello's case, as he dies he uses the handkerchief to cover his self-inflicted wound. Besides stressing the link between Othello's self-destruction and the screen the handkerchief has become, this gesture also returns us to the moment where Othello first receives the handkerchief from the wounded slave and, spurred on by her death, demonstrates his larger-than-life prowess as a fighter (and physical actor) in the slave rebellion. The lament is not so much for Desdemona as for Othello's own heroic potential. Indeed, it is tempting to read this exiled hero's death-by-projection in terms of the effects of Western mass media on non-Western cultures, an issue about which one might expect the Tsikurishvilis to be particularly sensitive. But Othello's death is not the whole story. Fittingly for a production so dominated by Iago's psychology, the final tableau features two of the three Iagos dying in the original Iago's arms, in a perverse pieta. It is as if these alter-Iagos are what Othello has fatally wounded when he stabs Iago with the projector in the final scene, and their deaths serve for Iago a sacrificial, redemptive function, allowing for his psychological reintegration, the exorcism of his projective demons. Indeed, as the lights fade he stares at the audience with, for the first time in the performance, an expression of grotesquely ecstatic joy. But as his face recedes into the darkness, we see his barely perceptible features slip into pain, as if in ever-so-fleeting recognition of the tragedy he has brought on others and on himself.

\section{PUNCHDRUNK'S SLEEP NO MORE}

Punchdrunk has taken a very different approach in its four post-textual Shakespeare productions, A Midsummer Night's Dream (2002), The Tempest (2003), The Firebird Ball (their Romeo and Juliet, 2005), and Sleep No More (their Macbeth, 2003 and 2009). Punchdrunk's approach to performance stresses immersion and interaction, combining elements of installation art, video gameplay, historical re-enactment, Grand Guignol- and theme 


\section{POST-TEXTUAL SHAKESPEARE}

parks with more conventional elements of physical theatre like mime, dance and music. ${ }^{18}$ Director/ designers Felix Barrett and Maxine Doyle locate their productions in vacant buildings in which they create elaborate environments through which audiences freely wander. Setting thereby becomes in many ways the dominant 'character'. Even so, Punchdrunk productions are not site-specific in the strictest sense, ${ }^{19}$ for they don't engage the specific history of the site; the audience's awareness of the building's former use adds semiotic 'texture', but that texture tends to be one element among many. Some of the spaces in the environment are installations in which mysterious collections of objects evoke a mood, hint at past events, or function as metaphors; these meticulously composed spaces present spectators with far more materials than they can possibly process. Scattered elsewhere throughout the site are live performances, fragments of narrative; in the case of Sleep No More, those performances were wordless, though recognizably from Macbeth. To follow a narrative thread, one must follow a performer as he or she pursues a character's path through the overarching story and the building. Indeed, one must take on faith that there is an overarching story, for it is physically impossible to see all of the performances going on throughout the site. This means that one's spectatorial choices profoundly shape one's experience of the production; since one is experiencing elements of the production in non-sequential order and often in fragments, one is constantly struggling to make sense of what one happens to encounter. ${ }^{20}$ Our growing awareness of an overwhelming excess of meaning and the necessary incompleteness of our experience is in fact an essential element in the production. Even so, built into the work's structure is a moment where all the actors, with spectators following them, converge in one space so that we can all witness a key event. Barrett and Doyle have spoken of this element as a 'crescendo', a sequence in which the events and resonances of the work culminate in a single, memorable dramatic image. ${ }^{2 \mathrm{I}}$ Besides providing an intimation of narrative climax and a focus for the performance's metaphorical associations, the 'crescendo' conveys the sense that there is some larger narrative we have all been in the midst of, though it remains just out of grasp. Adding to the synaesthetic quality of the experience is the use of music, sound, dramatic lighting, even touch and smell. The final scene of Sleep No More, for example, was performed in a dark, foggy room crowded with bristly pines and heavy with the scent of evergreen, with a musical score that conveyed a sense of oceanic ebb and flow as well as growing menace. Punchdrunk productions, in short, create

I8 Discussions of Punchdrunk's aesthetic can be found in Felix Barrett and Maxine Doyle of Punchdrunk, 'In the Prae-sens of Body and Space - The (Syn)aesthetics of Site-Sympathetic Work', in Machon, (Syn)aesthetics, pp. 89-99; 'Felix Barrett in Discussion with Josephine Machon' and 'Maxine Doyle in Discussion with Josephine Machon', in BST Journal, 7, posted at http://people.brunel.ac.uk/bst/volo7or/home. html (under 'Perspectives'); and a lecture by Colin Nightingale, Punchdrunk's Creative Producer, in PSFK's Good Ideas Salon, January 2009, posted at www.psfk.com/2009/03/ good-ideas-in-storytelling-from-good-ideas-london.html.

19 According to Josephine Machon ((Syn)aesthetics, p. 203), Felix Barrett prefers the term 'site-sympathetic' to describe the relationship in Punchdrunk productions between performance and venue. Properly speaking, a 'site-specific' performance could be performed only within a particular space, for the specific venue is essential to its meaning and character. Punchdrunk productions, by contrast, 'respond sensually' to their performance spaces, using their qualities as important ingredients or resources but perhaps not as crucial ones. Sleep No More, for example, premièred in London at the Beaufoy Building in Kennington in 2003; it then played in Boston in 2009-IO at the Lincoln School in Brookline. Both buildings were abandoned schools; the fact that they were spaces formerly inhabited by children is significant to the show's themes.

20 Maxine Doyle comments that 'it's great for us when people say that they feel like they were the only person having that experience and it felt like the first and only time that event happened in that way, when in actual fact it's happened hundreds of times over the course of a run' (Machon, (Syn)aesthetics, p. 96). That is, it is the contingent nature of the audience's experience, the sense that one has accidentally happened upon an event or meaningful detail in the site that others are missing, that contributes a special spontaneity and intensity to Punchdrunk productions. It also gives them considerable replay value, for a second experience of a Punchdrunk performance would by its nature almost certainly be different from one's first.

2I Machon, (Syn)aesthetics, p. 96. 


\section{DOUGLAS M. LANIER}

mysterious alternative worlds designed to stimulate pre-rational forms of cognition: tactile contact, instinctive response, imaginative association, fantasy. The entrance to the performance space for Sleep No More in Boston - an almost entirely unlit, claustrophobic passageway - suggests a maze without landmarks, precisely the kind of experience we are about to have, but more metaphorically it calls to mind a birth canal, as if we were returning to a more primal perceptual mode.

Macbeth is a fortuitous choice for Punchdrunk, for the play explores the psychological space between waking and dream. Sleep No More seeks to recover that uncanny imaginative state from a text now overly familiar to most viewers. Much of the Macbeth narrative is in fact performed (in fact, some scenes are performed more than once), but the audience's experience of it is fragmented and out of sequence. What emerges far more strongly than story are associative links that build as one explores the site. Felix Barrett says of Shakespeare's texts, 'I respond to the poetry, they're poetic texts. ${ }^{22}$ Maxine Doyle explains the matter in this way:

[Barrett]'s concept became about space and form rather than content. He felt dissatisfied by the way that the dialogue worked in spaces. He felt that it killed the magic and mystery of the event, that the images that he created were more evocative than the words. So that's why he sought out a choreographer to work with because he felt that physical language would work better. And then we made a wordless Macbeth... For me the text exists in the unseen words, it exists in the relationship and the exchange and the situations that the texts create. I think that's what's really powerful for me. Looking at Shakespeare, for example, the characters are so rich and the situations are so clear so that it's actually really easy to strip it down to its essence. ${ }^{23}$

The focus of Punchdrunk's approach to Shakespeare is not story, that narrative content which appeals most to the rational intellect, but rather the metaphorical richness of Shakespeare's writing, which, so Barrett and Doyle claim, engages more visceral and emotional registers of audience response. It is as if Shakespeare's dialogue and narrative serves merely as a vehicle for the kaleidoscopic welter of images his writing puts into play, images which in their engagement with so many senses and sheer density seek to transcend language and rational thought and which trace their origin to primal registers of emotional and imaginative experience. Doyle's concept of the 'unseen words' refers to those elemental qualities that lie behind and give power to those utterances at the surface of the received Shakespearian text. To get at those otherwise unseen essences, it is necessary to pare away Shakespearian dialogue from the performance of Shakespeare, lest one become fixated on the narrative or ideational content of the play. Rather, if theatre is to offer an experience rather than just a re-presentation of those qualities, it must communicate the essence of Shakespeare (or any other classical text) through an intense, semiotically rich, non-linear, interactive event which above all engages its audience through bodily perception. To be sure, this conception of the Shakespearian script participates in a long history of performance theory which values the ineffable and distrusts the textual, stretching from Lamb's comments about the unperformability of King Lear to Artaud's call for a theatre of cruelty to method acting's valuing of subtext over text. What distinguishes Punchdrunk's approach from forebears and predecessors is, first, its perhaps somewhat surprising commitment to classical repertoire and, second, its sheer daring, its willingness to take this re-conceptualization of Shakespeare performance to its logical (certainly not the right word) conclusion.

As the title Sleep No More implies, Punchdrunk's aim with its performance of Macbeth is to convey viscerally the inchoate sense of menace, doom, guilt and bodily violation that comes to haunt Macbeth and wife by providing a physical experience of the dreamlike space between waking and sleep, that state in which rationality is suspended, one's capacity for imaginative association and bodily perception is heightened and one's experience of reality seems disturbingly fluid and uncanny. Arguably it is

\footnotetext{
22 Machon, (Syn)aesthetics, p. 96.

23 'Felix Barrett in Discussion with Josephine Machon', BST Journal.
} 


\section{POST-TEXTUAL SHAKESPEARE}

this nightmarish state of mind that comes to dominate Shakespeare's play, as it becomes increasingly difficult to distinguish where Macbeth's psychological world ends and exterior reality begins. At the same time, however, this state of mind is enormously productive of potent images and deeply resonant webs of association, as if Macbeth's poetic imagination were awakened and freed from rational constraint by his sleeplessness. To create an experience of this menacing dreamspace, explains Barrett, 'we've lifted the quintessential images' and created from them 'an alternative physical and visual text of the play', ${ }^{24}$ in the process vastly multiplying the images' resonances. The site is filled, for example, with evocations of children we never directly see. One scene involves Macduff taking leave of his very pregnant wife; their home is figured as a Victorian doll's house. In one dark hallway is a starkly lit baby carriage, in which are wrapped two packages, suggestive of the children Lady Macbeth may or may not have had and perhaps of the murdered children of the play, as if ensconced in tiny coffins recast as 'gifts'. In another area is an exhibit which combines a defiled shrine of the Virgin Mary with a collection of children's shoes, the latter suggestive of the Holocaust. These and other evocations of children resonate with the abandoned schools within which performances of Sleep No More have taken place, spaces once inhabited by children and still heavy with their memory. Another group of elements concerns blood. Both Macbeth and Lady Macbeth bathe after Duncan's murder as spectators look on, and the tub they use becomes stained with blood. Elsewhere there is a room filled with tubs and medical equipment reminiscent of a primitive laboratory or taxidermist's in the only tub filled with water swims a huge leech. Babies and blood come together with forbidden desire and blasphemy in a terrifying scene in the basement. There, in uncomfortably close proximity to the audience, the witches perform an orgiastic dance amidst strobes, blazingly intense red lighting and deafening music, conjuring a horned, blood-covered demon who presents them with a tiny bloody babe. This cluster of associations blood, desire, blasphemy - surfaces again in the climactic banquet scene. In a perverse version of the Last Supper, the Scottish court enjoys a gluttonous banquet which slowly morphs into grotesque kissing and groping, until a bloody Banquo rises to terrify Macbeth, and he and Lady Macbeth separate the banqueters, among whom is Duncan himself. The slow-motion movements of the actors gives the scene a dreamlike and cinematic quality, but the aching pace also conveys psychological time as the guilt-ridden Macbeth experiences it in this scene. Soon afterward, the trees of Birnam Wood begin to move, and a darkly clad dancer leads Macbeth to the centre of the room, where he is hanged before our eyes - the climax of the performance. To add to the spectator's instinctive sense of irrational unease, throughout the venue are scattered references to folk superstitions, including items like mirrors, peacock feathers, hair, playing cards and salt. ${ }^{25}$

These images are set against a production design which often harkens to upper-class life in the twenties and thirties, an era in which aristocratic refinement still held sway but where upper-class political power had significantly eroded, a combination which invited decadence. Most of the principals of the cast are costumed in vintage formal wear, at least in the public spaces. On the lower floor of the building in the Boston performance are several rooms which resemble an ageing resort hotel with shabby-genteel furnishings; elsewhere is an elaborately detailed woman's boudoir of the same period. In the ballroom before the banquet is staged, couples in evening attire waltz to scratchy recordings of jazz tunes as a cryptic drama plays out between some of the characters.

24 Joan Anderman, 'Mystery Theater: British Troupe Punchdrunk Teams with the ART to Explode Theatergoers' Expectations', Boston Globe, 4 October 2009, posted at www. boston.com/ae/theater_arts/articles/2009/Io/04/sleep_no_ more_allows_audience_members_to_pick_their_own_show/.

25 These and other allusions to superstitions woven into the performance are catalogued in assistant director Paul Stacey's programme notes, 'Very Superstitious', posted at www.americanrepertorytheater.org/files/SNM\% 2oprogram\%2013_o.pdf. 


\section{DOUGLAS M. LANIER}

The strangely impassive aloofness of the dancers becomes more and more troubling as the scene progressed, as if they had become caught up in a decadent demi-monde of their own. Indeed, here the production seems obliquely reminiscent of elements from Stanley Kubrick's The Shining, a similar ageing resort haunted by images of its upper-class, murderous former occupants. The mannered and clearly faded elegance of this aristocratic milieu is in sharp contrast with the near-mad, irrational passions that we see on display in some of the private rooms. Macbeth and Lady Macbeth's bedchambers are relatively intimate in scale, forcing us close to the couple in their bed and bath, and the scenes they perform there suggest the intensity of the passions they share. Those who take the time to explore the Macbeths' domestic space discover in Lady Macbeth's effects letters which reveal her passionate relationship with Macbeth. When Lady Macbeth is overtaken by guilt, she quite literally begins to climb the bedroom walls and furniture in a frantic sequence of movements that conveys very effectively the interiorized claustrophobia of her guilt. The veneer of elegance in the performance's public spaces only serves to magnify the transgressive quality of the lust for power and blood that drives the action and the principals' guilt behind the scenes. Indeed, the contrast between superficial 'civilization' and the power of irrational states of mind accord with Barrett and Doyle's fascination with primal modes of cognition in their theorizing about Punchdrunk productions.

Even so, describing the production in this way risks making it seem a more coherent and rational experience than it is. For one thing, the associative links are more oblique and yet more powerful than I can convey here. What symbolic sense this world has we must make ourselves, using what we can remember of Macbeth as a guide, and yet the links we make have considerable depth because the site is so over-saturated with detail. What Barrett and Doyle are offering is a physical and visual analogue for the semantic plenitude of Shakespeare's poetry - an experiential poem. Moreover, the associations extend well beyond Macbeth to resonant images from visual culture at large. In addition to
Holocaust and Catholic iconography, the production evokes images from the myth of Icarus, Hammer Horror films, and Gothic romance, to name a few. The subplot of the production is taken from Hitchcock's Rebecca, with Mrs de Winter wandering through the building searching for her husband (who in this version is Duncan), all the while intimidated by Mrs Danvers. Besides being appropriate to the Sleep No More's production design, Hitchcock's film shares with Macbeth a prevailing Gothic mood, as well as a number of specific themes murder and guilt, isolation and secrecy, obsession and fear, the tension between aristocratic elegance and irrational passion, the haunting of the present by the past - and narrative motifs - phantom children, returning corpses, closed doors, the guilty tyrannical male, the witchy. But an equally important point of convergence with Macbeth is simply the uncanny, dreamlike quality of Hitchcock's visuals which drive the film's narrative. Indeed, Rebecca announces its concern with dream and memory with its famous opening line, 'Last night I dreamt I went to Manderley again', and much of its protagonist Mrs de Winter's experience in the film, particularly in Manderley, plays like some Gothic nightmare. Both Macbeth and Rebecca exemplify the kind of aesthetic content and intense yet ambiguous tone that Sleep No More seeks to explore, and they are also 'classics' which provide knowledgeable audience members with touchstones by which they can orient themselves as they try to make sense of the Sleep No More environment.

Like Macbeth (and Rebecca), Sleep No More addresses memory and perception. Not only does Sleep No More require us to remember the fragments we have seen in order to piece them into some idiosyncratic imaginative whole, it also reminds us how our experience of Macbeth has become inseparable from what Geoffrey O'Brien has called 'the phantom empire' of images that occupy the modern cultural imaginary, many of which descend from Shakespeare's play. ${ }^{26}$ That is, the performance traces forward and backward the

26 Geoffrey O'Brien, The Phantom Empire: Movies in the Mind of the 2oth Century (New York, I995). 


\section{POST-TEXTUAL SHAKESPEARE}

play's thematic and visual genealogy, addressing not just how Macbeth itself is semiotically oversaturated but also how culture at large is oversaturated with Macbeth. Central to Sleep No More's effect is its oceanic quality, the sense of being confronted with a semiotic space so detailed, vast and complex that it overwhelms our attempts to grasp it rationally. Although the production has a specific tone and thematic shape, its edges, as it were, seem to extend outward to the semiological horizon. Contributing to this sense of being adrift is the production's menacing soundtrack, which plays continuously throughout the performance. Though different themes play in different areas, the musical structure is predominantly one of ebb and flow, with rising volume and tension followed by release, over and over again. And because much of the soundtrack is lifted from Hitchcock films and cleverly reprocessed, the music seems tantalizingly familiar yet not quite identifiable, just out of reach of recognition. One last element of the production contributes to the kind of theatrical experience Sleep No More offers - the fact that spectators must wear white carnival masks and are forbidden to speak throughout the performance. The aim of this practice, claim the producers, is to make audiences feel more anonymous and thus less selfconscious about being so close to the players and more adventurous in exploring the performance space. ${ }^{27}$ The carnival masks can't help but evoke associations with the ominous voyeurs of Stanley Kubrick's film Eyes Wide Shut, but given the performance environment's resemblance to a largescale haunted house, the masks serve primarily to make the spectators into anonymous contemporary ghosts. This leads to an unsettling reversal of spectator and performance. Rather than we as spectators situated in present reality watching a theatrical re-presentation of the past created for our benefit, we become unreal traces from another time which haunt the real-time, bodily-present performance world before us, a performance which never acknowledges our existence and seemingly doesn't demand our presence in order to be performed. We become ghosts in the vast, Deleuzian semiotic machine that Macbeth has become, struggling to make sense of a world just outside our comprehension. The scramble of white-masked spectators to follow characters through dark hallways reminds us that the site, like Shakespeare's play, is haunted by our own voyeuristic fascination with horror and guilt and our scramble for significational mastery.

\section{BUT IS IT SHAKESPEARE?}

As limit cases for the performance of Shakespeare, the Synetic Theater's Othello and Punchdrunk's Sleep No More raise anew some of the foundational questions of performance criticism: what is the relationship of the Shakespearian text to performance? If these works do not perform the Shakespearian text, are they really Shakespeare performances and, if they are, how are they Shakespearian? What cultural forces and pressures are at work in the wordless form of these performances, and how (if at all) do they redraw the possibilities of what might be designated

27 Despite Punchdrunk's emphasis on immersion and interaction, the performance does place limits on where spectators can go and how they can engage with the performers. Some doors in the Sleep No More environment are locked or blocked off, suggesting, perhaps unintentionally, that there are areas out of sight where materials are displayed or performances are taking place; the inaccessible spaces, that is, may add to the sense that as spectators we are experiencing only part of a much larger whole. (The truth is that those areas no doubt serve as offstage areas for the actors or passageways which allow them to move unseen from one performance space to another.) Those spectators who take off their masks or who speak are reminded of the rules by minders dressed in black who discreetly monitor the audience's behaviour. Though in theory there is nothing to prevent spectators from physically engaging with the actors directly, in practice audiences tend quickly to adopt the position of voyeurs situated at a distance from the live performances, craning in only when the action the actor is performing is small-scale. Sometimes the actors push spectators aside as they move from one scene to another, but otherwise there is little contact between audience and performer. However, Julie Lipkin of the Cape Cod Times reports in her review how a teenager's picking up billiard balls from a pool table led to an extended interaction between actor and spectator; see Lipkin, 'Dream Team', Cape Cod Times, I4 November 2009, accessed on Lexis-Nexis, io November 20 Io. 


\section{DOUGLAS M. LANIER}

'Shakespeare'? One might even ask, in what sense do these performances really leave the Shakespearian text behind? Both companies, their directors claim, begin their production processes with close engagement with the Shakespearian text, though they proceed with markedly different assumptions and aims. Paul Stacey, assistant director for Sleep No More, goes so far in his programme notes as to claim that 'Every line of Shakespeare's Macbeth is embedded in the multiple languages - sound, light, design, and dance - of Sleep No More. ${ }^{28}$ As the performances evolve, however, Shakespeare's words are pared away as they are translated into visual, physical, musical and even architectural forms. Thinking of this process in terms of 'translation' (and of performance as, in Stacey's phrase, 'multiple languages') might prompt us to consider its relationship with linguistic translation. With translation of Shakespeare, we have become accustomed to thinking in terms of equivalence, approximation, analogy and creative reinvention as means by which a translator might bridge the gap between Shakespeare's language and the target language. Indeed, we have become increasingly comfortable with translations that do not aim for word-forword, image-for-image, even speech-for-speech fidelity. Is intermedial translation of Shakespeare, then, to be regarded as any different in kind from linguistic translation? As I've been suggesting, it is different at least in one way: it requires its practitioners explicitly to posit an essential Shakespeare of which Shakespeare's language is only a contingent textual manifestation. In the case of the Synetic Theater, that essential Shakespeare is to be located in the narrative and the characters' psychology, not the particular words the characters speak; in the case of Punchdrunk, it is located in particular primal feeling-states of guilt, fatedness and abjection which one experiences instinctually and bodily rather than rationally through Shakespeare's story and imagery, feeling-states which cannot be simply reduced to the text. All directors do this kind of positing of an essential Shakespeare, cutting, rearranging or rewriting passages they regard as extraneous to what they posit is a play's essential core. Paring away all of Shakespeare's text simply radicalizes the implications of that very routine performance process.

These wordless performances also raise the question of how audiences understand these performances. Do they recognize them as Shakespearian and, if so, how? In what sense 'Shakespearian'? Do these performances require or trade upon the audience's prior knowledge of the Shakespearian text? To put this another way, does the audience - or more precisely, the 'ideal spectator' - supply from memory the Shakespearian text that the performance excises? I saw the Synetic Othello with a companion who did not know the story, and she was able to follow the action readily and in detail. (Of course, one might object that the general shape of the Othello narrative is familiar enough from its diffusion in popular culture; whether that generalized pre-text is specifically Shakespearian would be a matter for some debate.) One measure of the Synetic Theater's skill, I would argue, is that one need not know the text or story beforehand, though perhaps certain moments - say, the allusion to the black ram and white ewe - are enriched by one's recognition of the reference. Whether or not Synetic's skills would be sufficient to perform a play narratively more complex and less familiar to audiences, say Timon of Athens or Cymbeline, would be interesting to test. The issue of reception is even more complex in the case of Sleep No More, where the narrative line is far less clear and the Shakespearian content less readily recognizable. Reviewers regularly remarked on the issue; Lyn Gardner, writing for The Guardian, notes that 'you will need more than a passing knowledge of [Macbeth] to make the connections' to Sleep no More, but goes on to say, 'I suspect that the experience is sufficiently novel that, even if you had never heard of the play, you would take a puzzled

28 Stacey, 'Very Superstitious'. Despite this claim, it seems very unlikely that even a well-seasoned Macbeth scholar would be able to identify where all of the lines are physically embedded in the sprawling production, particularly since it is impossible - by design! - to see the whole performance. In other words, the status of the Shakespearian text's (partial/absent) presence in the production needs to be carefully theorized. 


\section{POST-TEXTUAL SHAKESPEARE}

pleasure in the evening. ${ }^{29}$ Even the title, Sleep No More, seems to mark some distance from its Shakespearian source and perhaps refuses the label of being in some way properly 'Shakespearian'. A full discussion of reception would require examination of promotional materials, programmes and reviews, as well as audience surveys and their analysis, all well outside the scope of this article. But it is worth observing that the Synetic Theater and Punchdrunk have by and large preferred to work with 'classic' texts. On the one hand, it might be said that classical texts provide the requisite depth of narrative, characterization and imagery needed to support two hours of physical performance. ${ }^{30}$ On the other hand, undoubtedly some level of prior audience familiarity with the work is helpful in making the productions comprehensible and, equally important, commercially appealing. For Felix Barrett, the value of using classic texts is that they provide audiences with known cultural landmarks with which to orient themselves:

The reason why we use these great classics is, for a start the audience need a hook because the conventions take some getting used to. In order to empower the audience they need to feel that is a puzzle, a conundrum that they can grasp. They need to be able to piece together the history. That's why we never write a piece from scratch, there has to be that awakening, where it clicks for each individual. ${ }^{31}$

The crucial question becomes, then, what level or sort of prior familiarity with Shakespeare is needed for these wordless performances to 'click'? Is the familiarity one with the Shakespearian text per se, or does that familiarity spring from other sources? Though for the performers these productions may begin with the Shakespearian text, from the audience's perspective these performances actively refuse Shakespeare's long-standing association with text, and they depend upon a prior knowledge (if they depend on it at all) that is itself independent of close familiarity with the Shakespearian text. This is why I characterize these productions as instances of 'post-textual Shakespeare', for their relationship to the Shakespearian text is supplemental in the deconstructive sense, radically complicating that text's status as a locus for the 'essential' Shakespeare.

This discussion raises a third issue, one of the disciplinary authority to which Shakespeare scholars have traditionally laid claim. The founding gesture of professional Shakespeare study more than a century ago was to reject Victorian biographicalism and focus instead on establishing 'authentic' texts, texts which genuine scholars were obligated to establish and explicate with rigour and which, some performance practitioners aver, even provide detailed guides to their own performance. The equation of the 'essential' or 'authentic' Shakespeare with the Shakespearian text has become so routine that it has the force of common sense for Shakespearian professionals - I mean, what else would you study or appeal to? The growing reach of post-textual Shakespeare offers us an opportunity to reappraise the authority of the Shakespearian text, to trace how and why Shakespeare has migrated across various media and how those migrations relate to dominant and emergent social formations, to think more rigorously about where scholars, performers and the culture at large locate the 'essential' or 'real' Shakespeare and how and why they do so. Given the post-textualization of contemporary culture, it is time for Shakespearians to parse carefully and perhaps to reconsider their devotion to text. Shakespeare is not just any text but the text, one of our culture's secular scriptures, and so in the case of Synetic's Othello and Punchdrunk's Sleep No More, 'doing' Shakespeare wordlessly makes a powerful case that even his power springs from an elemental quality outside or before language, precisely the conviction that underlies the practices of physical theatre. Beyond their sheer virtuosity, what makes these productions fascinating and provocative is the way, by

29 'Review: Sleep No More', The Guardian, I7 December 2003, p. 26.

30 Felix Barrett states that 'the reason why we've used Shakespeare so much is because those descriptions, there's so much in there, so many moments, installations are described within the text it's just a matter of unpicking' ((Syn)aesthetics, p. 96).

${ }^{3}$ I 'Felix Barrett in discussion with Josephine Machon', BST Journal. 


\section{DOUGLAS M. LANIER}

their very claim to be 'doing' Shakespeare without words, they complicate long-standing assumptions about what is essentially Shakespearian, and thus complicate our assumptions about where Shakespeare's cultural value lies. Equally interesting is how these performances conceptualize and contextualize the putative universality of Shakespeare within contemporary mediatized culture, something Punchdrunk does with considerable agility.
These performances may be dumb (in the sense of wordless), but they are not dumbed-down or ineloquent, and judging from the crowds I saw at both shows, they speak, so to speak, to contemporary audiences. But are they Shakespeare? To ask this question is to contemplate our own disciplinary assumptions and to confront fully the conditions of Shakespeare's afterlife in an increasingly posttextual world. 